Brock Education

Vol 16, No. 2, 2007

\title{
A Systematic Process for Educational Policy Development: Based on a Systems Approach to Training and Project Management
}

\author{
Catherine M. F. Bates \\ Brock University
}

\begin{abstract}
In the Canadian Forces leadership is considered to be the paramount skill of all members. For Training Development Officers, one method of displaying leadership is through the careful consideration of educational policy and its skilful implementation. If we do not take the time to write carefully considered policy, then students and their issues are managed according to the values and beliefs of individual decision makers. Normally this is fine, but when it negatively impacts students or teachers then neither equality nor equity is achieved.

In the Canadian Forces we follow a systematic process for training development, but not for training and education policy development. The five characteristics of systematic policy development are discussed following a brief discussion of the different types of educational policy. The paper expands upon the five characteristics grouped under the following topics: an academic approach, communities of practice, educational leadership, change agentry, and an integrated model. An integrated model of policy development is proposed that is based on the consolidation of an environmental scanning model, the Canadian Forces Systems Approach to Training, the Project Management Institute Project Management Model, and Delaney's phases of policy implementation. It is recommended that the resulting model serve as a guide for Canadian Forces policy developers.
\end{abstract}

The Canadian Forces (CF) follows a systematic process for training development, but not for training and education policy development. In spite of this, we do training and education policy development. Our training and education policy developers require the same support and tools that we use as training developers. In this paper I will discuss how existing CF Individual Training and Education System (CFITES) and Department of National Defence (DND) Project Life Cycle processes, tools, and skills are applicable to the challenging but rewarding field of training and education policy development.

\section{Approach}

In this paper I will contrast the Project Management Institute (PMI) project life cycle process and the Canadian Forces Individual Training and Education System (CFITES) model (both will be explained in detail). The resulting integrated model will represent the best of both processes and contribute to educational and training policy

Catherine M. F. Bates is a Ph.D. student in the Joint Ph.D. program at Brock University, in the Policy and Leadership stream. 
equity. Educational equity is described by Delaney (2002) as "equality of educational opportunity" (p. 98). If we do not take the time to write carefully considered policy, then students and their issues are helped according to the values and beliefs of individual decision makers. Normally this is fine, but when it negatively impacts students or teachers then neither equality nor equity is achieved. My position is that educational equity can best be achieved through carefully considered and skillfully implemented policy.

\section{Purpose}

An integrated model of policy development is proposed as one method of policy development in the service of educational equity. A project management/ systems approach with which most instructional designers and project managers are familiar could form the basis for fair policies that promote justice in the education and training system. The practice of developing and implementing individual models for complementary processes does not take advantage of wider opportunities. Fullan (1993) reports that structural changes to existing processes require changes in ideas, beliefs, and attitudes, a willingness to examine the interconnectedness of all parts and to expend the effort needed to address the details of complexity, and a flexible process orientation. He cautions that the change required to affect policy requires a "complete change in organizational culture and in the organization's relation to other agencies" ( $p$. 54). The CF is currently undergoing an organization-wide Transformation Initiative that aims to take advantage of any and all opportunities for change while recognizing that cultural change will have to go along with any recommendation for process change. The proposed new policy development model built from existing models described in this paper is timely given the CF's favourable attitude to organizational change.

\section{Assumptions}

A discussion of the differences between practices, regulations, procedures, policies, and philosophies will ensure a common understanding of the terms used in the discussion that follows. Delaney (2002) differentiates between: practices (something everyone does, but they are not recorded anywhere), regulations (something specific and recorded to guide practice), procedures (how things are to be done, not what is to be done), mega-policies (a policy that sets guidelines for other lesser policies), metapolicies (how a policy will be developed), and philosophy (an approach towards a mandate or goal). The policy development model in the paper is intended mainly for the development of mega-policies.

The requirement for new or revised training and education policies in the $\mathrm{CF}$ are assumed to be in reaction to one or more of the following issues:

1. Needs assessment. One of the first steps in any systems approach to training is needs assessment. Needs assessment is defined as

the effort to understand a problem before selecting a solution, the systematic study of a problem or innovation incorporating data and opinions from varied sources in order to make effective recommendations or to propose valid solutions. It is a strategic level process that permits training staff to target 
needs that may best be addressed by training or by solutions other than training. (Department of National Defence [DND], 2006b, p. 19)

Needs assessment incorporates environmental scanning concepts and the problem definition stage of the policy development cycle.

2. Reaction to incident. From time to time, an organizational knee-jerk reaction is generated to a triggering event that raises an issue and necessitates hasty policy development. A recent CF example was the Somalia Inquiry and the generation of a zero tolerance policy on harassment and racism.

3. Emerging issue. Ideally, environmental scanning, demographic trend analysis, and careful research reveal emerging issues well in advance of the need for policy. The CF Recruiting System is very good at this, and collects huge amounts of data that are carefully analyzed to predict Canadian recruiting trends and to react to them with fair and comprehensive policy. An example of this was changes to entry level education standards in reaction to both higher levels of potential candidates' education and the requirement for higher levels of education to match increasingly difficult technology jobs (e.g. Aviation Systems Technicians, Fire Control Systems Technicians, and Naval Control of Shipping).

4. Due diligence. Due diligence is a legal concept widely promoted in environmental protection, responsibility, and sustainable development. By removing reference to the environment, the definition is as follows: "Due diligence is the reasonable standard of care of others that individuals shall exercise in the course of their actions and duties" (DND, 2006c, Definitions). Sometimes policies are required to protect corporate and individual interests. A triggering event may have occurred that highlighted the need for a policy to explain the organization's position, regardless of whether the event is likely to happen again. This is the training version of malpractice insurance.

5. Correction from processes to policy. Every organization has processes that are treated as de facto policies. Occasionally they must be converted to policies when these processes generate public examination. Public scrutiny in the CF could be in the form of Ministerial Inquiry, Redress of Grievance, or informal complaint. A formalization of course reporting procedures was required in Support Training Group when a student complained through his Member of Parliament after failing a course. He complained that his course report did not clearly state if he would be allowed to retake the course, and at which point he would re-enter the course.

\section{Building the Model}

Support for a systematic approach to educational policy development can be found in Leadership and Sustainability (Fullan, 2005). Fullan states that as "more and more leaders become system thinkers, they will gravitate toward strategies that alter people's system-related experiences: that is, they will alter people's mental awareness of the system as a whole, thereby contributing to altering the system itself' (p. 40). Fullan believes that systems thinking still has a long way to go which he attributes to systems working in isolation and that it is possible to gain cooperation between one group, such as teachers, but more difficult to gain cross-group cooperation among districts, governments and the public. He notes that it is possible for people to look beyond their own system for ideas, and finally, that success can only be ensured when 
systems are made accessible to people other than the specialists who promote and manage the system.

Ten years ago the promotion and management of a system by a small group of specialists was the order of the day within the CF through its systematic approach to training. Within the last ten years, the Manual of Individual Training, which is the process guide for the systems approach, was mainly written and used by Training Development Officers. When we responded to requests from our instructors, training managers, and standards officers for a more accessible guide, we rewrote it and supported it with ongoing training. While the elitism of the old manuals and process were unintentional, the outcome served to isolate the Training Development Officers who were meant to promote the widespread use of the systems approach. Most professional groups have unique and specialized processes. By looking outward and integrating these models, it might be possible for us as a profession of training developers serving the military community to combine the best aspects of each model and create something new that serves a wider community. The discussion that follows presents many different models, but compares and aligns them into one final cohesive model that represents a potential best practice for systematic policy development.

One method of detecting trends early enough to react to them is called environmental scanning. The process of environmental scanning is the first model that will build into the final systematic policy development model. The concept of environmental scanning is a method of collecting data, defining issues, and benchmarking. Benchmarking is defined as "the process of comparing and measuring an organization's operations or its internal processes against those of a best-in-class performer from inside or outside its industry" (Alstete, 1995, p. 1). After many years of fiscal restraint and the corresponding downsizing, the CF has finally reached a point where it is indeed impossible to do less with less. The CF Transformation Initiative has been launched to explore fundamental changes to the culture of our military to ensure a fully integrated and unified approach to operations (DND, 2006a). To support Transformation, environmental scanning has been re-introduced using strategic open source information. At a recent Human Resources Seminar on Environmental Scanning, I was encouraged by the message from both military and civilian intelligence professionals that we are fully committed to using open sources of information to scan the environment to define issues and develop policies. The converse of this process is exploring other system models and integrating them with our existing models. The result of this examination of social and political trends, market and competition trends, and technological trends is more informed policy (Bisson, 1997). DND, and the CF in particular, have no shortage of process models however none are currently integrated. The Strategic Open Source Information System model, shown below in Table 1, is the first step in a proposed policy development model. As the model builds, preceding models (such as the first one) will be shown in italics.

Project management is a systematic process managed by a professional organization called the Project Management Institute (2006) and described in the Project Management Book of Knowledge. The steps in this model are shown below in Table 2 beside the Strategic Open Source Information System model. 
Table 1. Integrated Model of Policy Development - Phase 1

\begin{tabular}{|l|}
\hline \multicolumn{1}{|c|}{$\begin{array}{c}\text { Strategic Open Source } \\
\text { Information System }\end{array}$} \\
\hline Direction \\
\hline Information Requirement \\
\hline Collection Plan \\
\hline Collect \\
\hline Compare \\
\hline Analyze \\
\hline
\end{tabular}

Table 2. Integrated Model of Policy Development - Phase 2

\begin{tabular}{|l|l|}
\hline \multicolumn{1}{|c|}{$\begin{array}{c}\text { Strategic Open Source } \\
\text { Information System }\end{array}$} & Project Life Cycle Model \\
\hline Direction & Concept \\
\hline Information Requirement & Planning \\
\hline Collection Plan & Design \\
\hline Collect & Development \\
\hline Compare & Implementation \\
\hline Analyze & Closeout \\
\hline
\end{tabular}

The Book of Knowledge is also the basis for a much sought after Project Management Professional Designation. There are many general textbooks on project management each promoting a version of this cycle. One popular book titled 5-Phase Project Management: A Practical Planning and Implementation Guide (Weiss \& Wysocki, 1992) divides the phases into planning and implementation that includes; define, plan, organize, control, and close. This model is similar to Delaney's and collapses the Design and Development phases into one called Organize. There is ample scholarly research conducted based on the Project Life Cycle Model, however, few university libraries hold the Journal of Project Management in which the articles are published. In reviewing the abstracts of the many journal articles discussing the practical application of the Project Life Cycle Model, it is clear that integration has not yet been attempted. In fact, most articles are of the case study variety.

The Canadian Forces Individual Training and Education System (CFITES) Manual of Individual Training is a thirteen-volume process guide that covers all of the six phases of our systematic approach to training (DND, 2006b). Some phases such as development and design have more than one volume to support it. There are additional volumes on prior learning assessment, a stand-alone policy volume, and a project management volume. The volume on project management does not attempt an integration of tasks, skills and knowledge used by instructional design professionals or training managers. It does reference the Project Management Institute Project Life Cycle Model. The six phases of the CFITES systematic approach to training are 
Table 3: Integrated Model of Policy Development - Phase 3

\begin{tabular}{|l|l|}
\hline Project Life Cycle Model & \multicolumn{1}{|c|}{$\begin{array}{c}\text { CFITES Systematic Approach to } \\
\text { Training Model }\end{array}$} \\
\hline Concept & Analysis \\
\hline Planning & No similar process \\
\hline Design & Design \\
\hline Development & Development \\
\hline Implementation & Conduct \\
\hline Closeout & Evaluation and Validation \\
\hline
\end{tabular}

Table 4. Integrated Model of Policy Development - Phase 4

\begin{tabular}{|l|l|}
\hline $\begin{array}{c}\text { CFITES Systematic Approach } \\
\text { to Training Model }\end{array}$ & \multicolumn{1}{c|}{ Policy Development Cycle } \\
\hline Analysis & $\begin{array}{l}\text { Identification of need } \\
\text { Review existing policies }\end{array}$ \\
\hline No similar process & $\begin{array}{l}\text { Gather information } \\
\text { Study, deliberate and determine } \\
\text { basic issues }\end{array}$ \\
\hline Design & $\begin{array}{l}\text { Draft, revise and rewrite. Discussion } \\
\text { and deliberation by stakeholders }\end{array}$ \\
\hline Development & Final revision and legal review \\
\hline Conduct & Communication and Implementation \\
\hline Evaluation and Validation & $\begin{array}{l}\text { Evaluation and revision, updating, } \\
\text { and improvement }\end{array}$ \\
\hline
\end{tabular}

show below in Table 3 beside the applicable phases of the Strategic Open Source Information System and the Project Life Cycle Model.

Delaney's Educational Policy Studies: A Practical Approach (2002) similarly promotes a systematic approach to policy development. While each chapter discusses a phase in the Policy Development Cycle (analysis, development, implementation, evaluation, dissemination), the consolidated list of the steps in the Policy Development Cycle described by Delaney (pp. 53-54) are more descriptive. This model is shown below in Table 4 beside the third model.

A similar policy development and research cycle was investigated for the Southern Africa Consortium for Monitoring Educational Quality. It starts with policy concerns, moves through a highly systematic and focused applied research cycle, and then is completed with research-based suggestions about how to address the initial policy concerns (Saito, 1999, p. 3). This study employed project management methods to manage the research, but did not report on any integration with their proposed policy development cycle. The concept of appropriating best practices from the business world into education is proposed in Glatter's article From Juggling to Struggling (1999) on head teacher training in the UK. One of the article's conclusions is that the management of people and human relationships is of vital importance in all 
business concerns as well as educational leadership. Within this same article, Fullan is quoted as recommending that:

Leaders for change get involved as learners in real reform situations. They craft their own theories of change, constantly testing them against new situations. They become critical consumers of management theories, able to sort out promising ideas from empty ones. They become less vulnerable to and less dependent on external answers. (cited in Glatter, p. 9)

I believe that this lends support to the practice of looking outward discussed in environmental scanning and again, while not recommending a preferred management practice applied to educational leadership, it does support the concept especially in terms of benchmarking our own practices. Wallace (2001) injects a note of caution regarding benchmarking leadership practices to other organizational models. He comments that a culture of realism within the educational organization is necessary when looking outward. He notes that this culture must:

Encompass the nature of the task we are setting ourselves; our complementary and contradictory interests; the compromises that all partners will have to make and how to make them; the debates where we may agree to differ and the ones where we must agree to agree; and the extent and limits of what we can expect to achieve. (p. 2)

Realistic expectations when looking to general management models for their applicability to education would seem a wise move, however the endorsement of looking at other models was again echoed in Ribbins (1999) with recommendation number six to enable a "redefinition of the field of education management and leadership in the light of the major changes in practice that have taken place since the $1980 \mathrm{~s}$ " (p. 3). This recommendation is "to assess and redefine the contribution of general management theory to practice in educational contexts" (p. 3, italics in original).

\section{Critical Analysis}

An Integrated Policy Development Model is described in Table 5. This model shows the interrelated phases of the Strategic Open Source Information System as a contrast to a third model, the Project Lifecycle Model and the CFITES Systematic Approach to Training Model. A rough approximation of the phases of these models is contrasted with the Policy Development Cycle. The purpose of this table is to show the similarities of all of these models. A common nomenclature of these phases is assigned based on the reasons why policy might be required (discussed above in assumptions). An integrated model applied to policy would be termed a meta-policy by Delaney as one in which the method of policy development is described. This model is suitable for mega-policies that depict the performance of other minor policies, and could also serve as a guide to developing regulation, processes, and practices. The intent here is to demonstrate that the approaches used by similar professionals are related and the same skills that are brought to bear on projects and training apply to policy development.

Only few systems approaches are linear as the integration in Table 5 suggests. Reality would require something more iterative as shown in Figure 1. 
Table 5. Integrated Model of Policy Development - Integration

\begin{tabular}{|l|l|}
\hline \multicolumn{1}{|c|}{ Policy Development Cycle } & $\begin{array}{l}\text { Integrated Policy Development } \\
\text { Model (common nomenclature) }\end{array}$ \\
\hline $\begin{array}{l}\text { Identification of need } \\
\text { Review existing policies }\end{array}$ & Identify issue \\
\hline $\begin{array}{l}\text { Gather information } \\
\text { Study, deliberate, and determine basic } \\
\text { issues }\end{array}$ & Plan approach \\
\hline $\begin{array}{l}\text { Draft, revise, and rewrite Discussion and } \\
\text { deliberation by stakeholders }\end{array}$ & Conduct research \\
\hline Final revision and legal review & Draft policy \\
\hline Communication and Implementation & Issue policy \\
\hline $\begin{array}{l}\text { Evaluation and revision, updating, and } \\
\text { improvement }\end{array}$ & Verify policy \\
\hline
\end{tabular}

\section{Synthesized Resolution}

Policy development is too critical a task to leave to chance. While most policy developers follow an intuitive method, the adoption of a systematic approach will satisfy the concept of due diligence in the performance of the task of policy development and result in policy that can not be confused with process, regulation, practice, procedure, or philosophy. As Delaney (2002) states, "systemic reform approaches offer another possibility for those disappointed by policy, an approach to policy that combines centralized leadership around outcomes with decentralized decision making about practice" (p. 112). The integrated systems approach to policy development recommended in Table 5 and Figure 1 applies the tasks of different

Figure 1: Integrated Policy Development Model - Iterative




Table 6. Five Characteristics of Systematic Policy Development

\begin{tabular}{|l|l|}
\hline Characteristic & Impact on policy development \\
\hline Academic Approach & $\begin{array}{l}\text { Research based goals for changes in educational } \\
\text { practice and organization through researching, } \\
\text { reporting and publishing. }\end{array}$ \\
\hline Communities of Practice & $\begin{array}{l}\text { Working models of new practice and professionally } \\
\text { accessible knowledge attained through } \\
\text { benchmarking, networking, collecting best } \\
\text { practises (usually positive), and collection lessons } \\
\text { learned (sometimes negative). }\end{array}$ \\
\hline Educational Leadership & $\begin{array}{l}\text { A centralized/ decentralized process that recognizes } \\
\text { the issues and triggering events that indicate a need } \\
\text { for new or revised policy. }\end{array}$ \\
\hline Change Agentry & $\begin{array}{l}\text { A coherent, sustained, change oriented political } \\
\text { process. Uses skills of legal advisor, subject matter } \\
\text { experts, stakeholders, and sponsors. }\end{array}$ \\
\hline Integrated Model & $\begin{array}{l}\text { Promoted through the regular assessment of } \\
\text { educational inputs, outcomes, and processes. }\end{array}$ \\
\hline
\end{tabular}

disciplines to the profession of policy development. Professionals from the fields of training development and project management already possess the skill and knowledge necessary to successfully develop policy. These might include; facilitation skills, research skills, communication skills, problem solving skills, knowledge management, and interviewing skills. An integrated model supports them by taking advantage of the five characteristics of policy development based on Delany $(2002$, p. 112) and described in Table 6.

The five characteristics of systematic policy development can be well managed by a clearly assigned Policy Development Team Leader/Manager. This person must be identified early to attend to the group dynamics of a team this diverse. When the five characteristics are compared with the Integrated Policy Development Model discussed throughout this paper, a final model emerges (Table 7).

Table 7: Integrated Policy Development Model - Final

\begin{tabular}{|l|l|}
\hline $\begin{array}{l}\text { Integrated Policy } \\
\text { Development Model }\end{array}$ & $\begin{array}{l}\text { Characteristics of Systematic } \\
\text { Policy Development }\end{array}$ \\
\hline Identify issue & Educational leadership \\
\hline Plan approach & Academic approach \\
\hline Conduct research & Communities of practice \\
\hline Draft policy & Communities of practice \\
\hline Issue policy & Change agents \\
\hline Verify policy & Integrated model \\
\hline
\end{tabular}

\section{Conclusion}

The CF follows a systematic process for training development, but not for training and education policy development. This does not mean that we do not value 
policy development. We do appreciate that our training and education policy developers require the same support and tools that we use as training developers. This approach reflects my belief that to promote equity and justice, policy should support the students and teachers and be fair and well researched. The regulations and processes can then be customized according to local needs and desires. This puts decision making back into the hands of educational leaders, but with guiding policies to support their decisions. The stove piping of individual systems does not take advantage of wider opportunities and reflects Fullan's (2005) call for an interconnected but flexible process orientation to policy development. The CF Transformation initiative aims to take advantage of any and all opportunities for change while recognizing that cultural change will have to go along with any recommendation for process change.

In this paper I proposed that the existing CF Individual Training and Education System (CFITES) and Department of National Defence (DND) Project Life Cycle processes, with inputs from other familiar models, represent tools and skills that are applicable to the challenging but rewarding field of training and education policy development. Through the integration of existing process models, the skills and knowledge of related professionals can be applied to the task of educational policy development through familiar and tested methods.

\section{References}

Alstete, J.W. (1995). Benchmarking in higher education: Adapting practices to improve quality. ASHE-ERIC Higher Education Reports, Report Number 5, Washington DC: The George Washington University.

Bisson, B.G. (1997). Human resource management concepts: Environmental scanning learning object. Retrieved August 26, 2007, from http://www.unb.ca/jhsc/ resourcectr/TME_courses/tme3113/human_resources

Delaney, J. (2002). Educational policy studies: A practical approach. Calgary, AB: Detselig Enterprises.

Department of National Defence. (2006a). A role of pride and influence in the world: Defence policy statement. Retrieved April 1, 2006, from http:// www.forces.gc.ca/site/reports/dps/main/intro_e.asp

Department of National Defence. (2006b). Canadian forces individual training and education system manuals of individual training. Ottawa, ON: Queens Printers in Right of Canada.

Department of National Defence. (2006c). Environmental protection and stewardship. Retrieved August 26, 2007, from http://www.admfincs.forces.gc.ca/admfincs/ subjects/daod/4003/intro_e.asp

Fullan, M. (1993). Change forces: Probing the depths of educational reform. London: The Falmer Press.

Fullan, M. (2005). Leadership \& sustainability: Systems thinkers in action. Thousand Oaks, CA: Corwin Press. 
Glatter, R. (1999). From struggling to juggling: Towards a redefinition of the field of educational leadership and management. Educational Management and Administration, 27(3), 253-266.

Project Management Institute. (2006). Project management book of knowledge excerpts. In Project estimating and scheduling participant manual. Washington, DC: The George Washington University.

Ribbins, P. (1999). On redefining educational management and leadership. Educational Management and Administration, 27(3), 227-238.

Saito, M. (1999). A generalizable model for educational policy research in developing countries. Retrieved August 26, 2007, from http://home.hiroshima-u.ac.jp/cice/ saito.PDF

Wallace, M. (2001). Really good ideas? Developing evidence-informed policy and practice in educational leadership and management. Educational Management and Administration, 29(1), 27-34.

Weiss, J.W., \& Wysocki, R.K. (1992). 5-phase project management: A practical planning and implementation guide. Reading, MA: Addison-Wesley. 